\title{
PROGRAMA CAPACITAÇÃO RURAL - SEBRAE/SP: METODOLOGIA, APLICAÇÃO E PESQUISA DE OPINIÃO COM OS PARTICIPANTES ${ }^{1}$
}

\author{
Ricardo Firetti ${ }^{2}$, Marcelo Machado de Lucca Oliveira Ribeiro ${ }^{3}$, Raul Franzolin Neto ${ }^{3}$ \\ ${ }^{2}$ APTA Polo Alta Sorocabana - Presidente Prudente - SP. E-mail: rfiretti@apta.sp.gov.br \\ ${ }^{3}$ Faculdade de Zootecnia e Engenharia de Alimentos/USP - Pirassununga - SP
}

\section{RESUMO}

No meio rural, as atividades de difusão de tecnologias têm a finalidade de prover os produtores com conhecimentos que possam: adaptar, transformar ou maximizar os fatores de produção encontrados nas propriedades rurais, geralmente, com a finalidade de melhorar as condições de vida dessas pessoas. Neste sentido, o SEBRAE/SP oferece um programa destinado à capacitação gerencial de produtores rurais que possui metodologia diferenciada, contribuindo para a profissionalização na gestão das propriedades rurais. Assim, o objetivo deste trabalho foi desenvolver uma pesquisa exploratória sobre o Programa Capacitação Rural - SEBRAE/SP que permitisse analisar e compreender sua metodologia, as diferentes formas de aplicação e avaliar a opinião dos participantes sobre a ação de capacitação. Para tal, foram utilizadas combinações de técnicas de análise qualitativa e quantitativa (análise estatística multivariada) a partir de entrevistas com instrutores do programa e aplicação de questionários aos participantes. Os resultados indicaram que o programa lida diretamente com a mudança de comportamentos, atitudes e valores pessoais de seus participantes em busca da valorização do produtor rural, e da necessidade de visão empresarial na condução das atividades agropecuárias. A pesquisa de opinião mostrou níveis de aprovação elevados em grande parte das variáveis analisadas, com destaque para o conteúdo abordado no programa, as atividades realizadas em grupos e o nível de satisfação dos participantes.

Palavras-chave: administração rural; agropecuária; comercialização agrícola; estatística multivariada; produtor rural.

\section{PROGRAMA CAPACITAÇÃO RURAL - SEBRAE/SP: METODOLOGY, APLICATION AND OPINION RESEARCH ON PARTICIPANTS}

\section{ABSTRACT}

In the agricultural way, the activities of diffusion of technologies have the purpose to provide the producers with knowledge that can adapt, transform or maximize the found factors of production in the country properties, generally, with the purpose to improve the conditions of life of these people. In this direction, the SEBRAE/SP offers a program destined to the managemental qualification of agricultural producers that possesses differentiated methodology, bringing, as contribution to the agricultural sector, the professionalization in the management of the country properties. Thus, the objective of this work was to develop an explorative research on the "Programa Capacitação Rural"- SEBRAE/SP that it allowed to understand your methodology, the different forms of applications, and to estimate the opinion of participants about capacitating action. To this end, we used combinations of techniques for qualitative and quantitative analysis (multivariate analysis) from interviews with instructors of the program and questionnaires to participants. The results had indicated that the program deal directly with the change of behaviors, attitudes and personal values of its participants in search of the valuation of the agricultural producer, the biggest professionalism and the necessity of enterprise vision in the conduction of the farming activities. The opinion research to a large extent showed high levels of approval of the analyzed variables, with prominence for the boarded content in the program, the group activities and the level of satisfaction of the participants. Keywords: agriculture; agricultural marketing; farmers; multivariate statistics; rural management.

\footnotetext{
${ }^{1} \mathrm{O}$ trabalho integra a dissertação de mestrado do primeiro autor.
} 


\section{INTRODUÇÃO}

Os programas e projetos de capacitação, destinados ao ambiente rural, na sua maioria, são reconhecidos pela simples transferência de tecnologia e de conhecimentos sobre determinada técnica de produção. Poucos são os exemplos que ensinam os produtores a administrarem de forma eficiente suas atividades de produção, como nos moldes daqueles aplicados às empresas urbanas.

A literatura aponta grande necessidade de investimentos em ações de capacitação aos produtores rurais (ABRAMOVAY, 2004), identificando carências nas metodologias praticadas (MAALOUF, 1993), sendo a maior parte dos trabalhos científicos sobre o tema centrado nas atividades formadoras desenvolvidas pelos programas do SEBRAE/SP, tanto o "Sistema Agroindustrial Integrado", como o "Programa Capacitação Rural" (CAMPOS, 2008; VIERA; NITZCHE; KOLLER, 2006; OLIVEIRA, 2008; SOUSA; SANT'ANA; TARSITANO, 2008; LOURENZANI; PINTO, 2008).

Teodore Shultz, Prêmio NOBEL de Economia, em sua obra "A transformação da agricultura tradicional", editada no Brasil em 1965, já apontava que, embora a agricultura tradicional pudesse ser considerada eficiente e não obstante já tivesse alcançado seu ponto de equilíbrio, seria necessário para que obtivesse ganhos de competitividade, que incorporasse novas tecnologias no processo produtivo associadas à capacitação da mão de obra envolvida.

Entretanto, desenvolver atividades de difusão de conhecimentos não é tarefa das mais fáceis, devido aos diversos fatores que compõem esta prática. São necessárias pessoas preparadas para desenvolver a função de repasse da informação, metodologia e infraestrutura adequada, e principalmente, o correto planejamento da ação de difusão, etapa mais importante do processo e por vezes a que menos recebe atenção. Todo este esforço deve ser desprendido para assegurar que o processo de comunicação entre as pessoas, durante a atividade de difusão, não seja prejudicado (FIRETTI; RIBEIRO, 1999).

Com a transformação ocorrida na produção agropecuária brasileira, hoje conhecida como "agronegócio", responsável direta pelo sucesso em diversos indicadores econômicos do país, os empresários rurais passaram a necessitar de auxílio para aprimorar a condução de seus negócios. Afinal, segundo Batista Júnior (1998) em função da política econômica delineada nos últimos anos, a correta gestão dos negócios, seja qual for sua natureza, passou a ter grande relevância.

Atento a esta necessidade o SEBRAE passou, em 1991, a atuar no agronegócio brasileiro com o intuito de auxiliar micro e pequenos empresários do setor rural naquilo que é a sua especialidade: fornecer subsídios gerenciais e mercadológicos de forma similar à sua atuação no meio urbano (SOARES, 1998).

O SEBRAE/SP, entre 1997 e 2007, ofereceu, dentro de sua rede de treinamentos, um programa destinado à capacitação gerencial de produtores rurais, o "PROGRAMA CAPACITAÇÃO RURAL" que possuía uma metodologia diferenciada de difusão de conhecimentos, e pretendia trazer, como contribuição ao setor rural, a profissionalização na gestão das propriedades rurais, promovendo mudanças de comportamento, atitudes e valores. O Programa Capacitação Rural (PCR) originou-se no Estado do Rio Grande do Sul numa iniciativa do SEBRAE daquele estado. Os primeiros esforços norteadores do programa partiram da Universidade Federal de Santa Maria (UFSM), que realizou, no início da década de 1990, uma pesquisa sobre as diversas informações demandadas pelos produtores rurais gaúchos, 
visando identificar os principais tipos de informações e 0 perfil dos produtores interessados (SEBRAE/SP, 2003a).

Segundo o SEBRAE/SP (2001), o público alvo do "Programa Capacitação Rural" possui um ritmo diferente de aprendizagem em função de seu desenvolvimento como ser humano e pelas experiências vividas, requerendo 0 uso de linguagem direta e de experiências concretas. A prontidão para aprender torna-se fortemente orientada para as tarefas condizentes com seus papéis sociais, uma vez que é capaz de identificar suas próprias necessidades de aprendizagem, deixando de vê-la como algo centrado em matérias para passar a enxergá-las como fonte de solução de problemas da realidade.

Desta forma, o ritmo de aprendizagem de adultos requer uma metodologia diferenciada, além de oferecer situações não ameaçadoras de aprendizagem. Sua motivação se liga às expectativas de melhoria na vida profissional, no reconhecimento social por um curso concluído e na busca do crescimento pessoal, que previamente deve ser despertada nos indivíduos.

De acordo com a Unidade Organizacional de Eduação da Cultura Empreendedora do SEBRAE/SP (UOEDCE, 2001) o objetivo do Programa é capacitar empresários rurais para administrarem suas propriedades como empresas, otimizando e controlando os recursos externos e internos, procurando maximizar o uso dos mesmos, estabelecendo metas e objetivos, sem desconsiderar os aspectos da preservação dos recursos naturais.

O público alvo é composto por micro, pequenos e médios produtores ou empresários rurais, sendo os profissionais contratados pelo SEBRAE/SP (facilitadores) credenciados a desenvolver atividades em módulos específicos, em razão de suas habilidades e experiência, de acordo com o processo previsto no Regulamento de Credenciamento de Facilitadores do UOEDCE (SEBRAE/SP, 2003b).

De acordo com Firetti; Franzolin e Ribeiro (2006), a estrutura do programa é composta por quatro fases: Visita Técnica e Sensibilização (10 horas); Repasse da Metodologia (80 horas) que inclui os módulos de Organização Social (20 horas), Custos de Produção (20 horas), Comercialização Agrícola (20 horas) e Administração Rural (20 horas); Acompanhamento (20 horas) e Encerramento.

Ao final de cada módulo de treinamento, os participantes fazem uma avaliação de diversos pontos que compuseram a ação de difusão em questionário específico elaborado pela UOEDCE - SEBRAE/SP.

$\mathrm{Da}$ maneira como é estruturado, o programa é um processo iniciado na fase de visita técnica e sensibilização que termina somente com o fechamento no segundo acompanhamento. Cada etapa subseqüente foi delineada para tornar-se complementar a anterior, aproveitando inclusive as atividades realizadas. Isto aumenta a complexidade do programa, devido, a sintonia que deve existir entre os facilitadores que se sucedem, exigindo maior padronização para não ocorrer equívocos, perda de eficiência ou mesmo problemas com a credibilidade da instituição SEBRAE/SP e dos profissionais envolvidos.

A metodologia utilizada no programa, dado as características do público alvo, tem enfoque participativo, com dependência nas características regionais, respeitando os principais problemas, culturas e vivências do grupo a ser capacitado. Os facilitadores que atuam no programa não são apenas transmissores de conhecimentos, mas também criadores e intérpretes das informações geradas no contato direto com seu público de trabalho (SEBRAE/SP, 2000).

Cada vez mais, programas de difusão no meio rural vêm utilizando novas metodologias, 
andragogia e até programação neurolingüística, como, além do citado Programa Capacitação Rural - SEBRAE, o Programa Qualidade Total Rural - SEBRAE, o Projeto MaisLeite (FIRETTI ; RIBEIRO, 2001) e os Projetos MaisCarne e MaisGrão (APEC TREINAMENTOS, 2003).

Posto isto, o objetivo deste trabalho foi estudar o caso do Programa Capacitação Rural SEBRAE/SP, permitindo compreender 0 desenvolvimento das ações de capacitação, as relações entre a metodologia empregada no programa e seu público alvo, e principalmente avaliar a satisfação dos participantes em relação a essa metodologia.

\section{MATERIAL E MÉTODOS}

A coleta de dados da pesquisa foi realizada por meio da investigação de informações secundárias, presentes em registros internos do Departamento de Agronegócios do SEBRAE/SP e do levantamento de dados principais através do acompanhamento das atividades realizadas na execução do programa visando abordar os demais objetivos da pesquisa. Este processo é indicado por Kotler (1996).

Assim, os dados principais foram coletados, no período de 14 de janeiro a 14 de setembro de 2003, através da observação da ação de capacitação e aplicação de questionários em 24 municípios paulistas, a seguir: Ituverava, Patrocínio Paulista, Analândia, São José do Rio Pardo, Vargem Grande do Sul, Pirassununga, Corumbataí, Santa Isabel, Salesópolis, Campinas, Santa Bárbara do Oeste, Porto Feliz, Peruíbe, Piedade, Capela do Alto, Ribeirão Grande, Itapeva, Riversul, Santa Cruz do Rio Pardo, Novo Horizonte, Irapuã, Catanduva, Mirassol e São José do Rio Preto.

\section{a) Análise da aplicação metodológica do programa}

Foram realizadas 30 observações presenciais, assistemáticas e não-participativas (ALMEIDA, 1989), sendo 24 em ações de capacitação e outras 06 observações presenciais em ações preparatórias e de fechamento. Desta maneira, foram analisadas a aplicação da metodologia do projeto, os processos de comunicação e os processos de interação dos participantes.

Com essas observações foi possível visualizar 0 contexto do processo social desenvolvido no projeto, possibilitando uma integração empática com o próprio objeto de estudo que implicou na melhor compreensão do fenômeno, exatamente como descrito por Wildemuth (1993).

b) Pesquisa de opinião com os participantes em relação ao processo de capacitação

Para a pesquisa de opinião foram aplicados 467 questionários (24 módulos de diferentes cursos) com perguntas fechadas de múltipla escolha (ALMEIDA, 1989; COBRA, 1992) sobre o Programa Capacitação Rural a constar: metodologia (enfoque participativo e jogos); recursos áudio visuais (preferência); material impresso (qualidade do material, conteúdo e clareza); facilitadores (relacionamento e clareza); nível de satisfação e adoção do conhecimento.

A elaboração definitiva do questionário ocorreu após a análise descritiva do projeto, e depois de testes iniciais numa amostra-piloto de pessoas a fim de eliminar dúvidas e proporcionar a reformulação das questões (ALMEIDA, 1989; COBRA, 1992; KOTLER, 1996).

O preenchimento dos questionários ocorreu após as atividades de capacitação e os dados obtidos foram submetidos à Análise Multivariada, especificamente, a Análise de Correspondência no Aplicativo STATÍSTICA 6.0 da StatSoft Inc. 
A Análise de Correspondência (AC), proposta em 1960 por Benzécri e citada por Bourruche e Sapora (1980), tornou-se um ótimo instrumento para análise qualitativa devido às suas propriedades matemáticas e pela riqueza de suas interpretações.

A AC é uma técnica de análise exploratória utilizada para estudar as associações entre duas ou mais variáveis categóricas, permitindo a visualização das relações entre linhas e colunas num mesmo espaço gráfico (SILVA; VERDINELLI, 1997). Através desta análise procura-se encontrar as relações recíprocas e as associações e oposições entre variáveis ou entre objetos e variáveis (BENZÉCRI, 1973).

Nos casos em que uma das variáveis possuía apenas dois itens de resposta, foi necessário utilizar uma técnica similar, de múltipla correspondência, que possui basicamente a mesma finalidade da análise de correspondência e indicada pelos autores Silva e Verdinelli (1997).

\section{RESULTADOS E DISCUSSÃO}

\section{a) Análise da aplicação metodológica do programa}

Foram acompanhadas 30 ações do Programa Capacitação Rural (PCR), sendo elas, 2 sensibilizações, 24 módulos (6 de cada) e 4 acompanhamentos (2 de cada), no período de 14 de janeiro a 14 de setembro de 2003. Cada módulo representava um curso de capacitação diferente, com grupos diferentes, no intuito de investigar a maior gama possível de participantes e localidades.

Os 24 módulos representaram entre 16 a $18 \%$ do total de cursos de capacitação realizados no Estado no período de pesquisa (em torno de 150 cursos), já que cada módulo acompanhado, a título de pesquisa, representava um curso.

O agendamento dos cursos do PCR era realizado pelos Escritórios Regionais do
SEBRAE/SP, com no mínimo 30 dias de antecedência, respeitando um sistema de rodízio entre os facilitadores. A agenda de cursos e módulos era repassada, mensalmente, pelo Departamento de Agronegócios do SEBRAE/SP, localizada na sede da entidade em São Paulo, na pessoa da Srta. Renata Rodrigues de Almeida.

Os módulos foram selecionados aleatoriamente (com exceção do módulo em Pirassununga), respeitando os limites geográficos impostos pela ajuda de custo do SEBRAE/SP. Os contatos posteriores foram realizados, na maioria das vezes, diretamente com os Agentes de Desenvolvimento do programa Sistema Agroindustrial Integrado - SEBRAE/SP (SAI), responsáveis pelas ações.

A maior demanda por cursos do PCR derivam das atividades desenvolvidas pelo Sistema Agroindustrial Integrado. Com isso, os profissionais ligados à rede do SAI, principalmente os Agentes de Desenvolvimento, que lidam diretamente com os produtores rurais, têm direta e efetiva participação no planejamento da ação de capacitação, pois cabe a eles, além da formação dos grupos, a articulação política municipal para angariar verbas que minimizem a despesa dos participantes com o curso, providenciar local adequado para a realização da ação, assim como os alimentos consumidos nos intervalos (coffe break) e nos períodos destinados ao almoço ou jantar.

Todo o material de apoio, inclusive equipamentos audiovisuais, materiais didáticos (participantes recebem uma apostila de cada módulo e bolsa estilizada do programa) e outros itens utilizados nas atividades de grupo e dinâmicas, são de responsabilidade dos Escritórios Regionais, ou se for o caso, dos Agentes do SAI responsáveis pela articulação da ação. No programa são utilizados: quadro negro/branco, cartazes em álbum seriado, retroprojetor, aparelhos de TV e vídeo cassete e, 
em alguns casos (ao critério do facilitador), aparelhos de som.

O acompanhamento da aplicação do programa foi realizado, em grande parte das vezes, de forma não participativa, ou seja, a fim de interferir o menos possível nas relações entre participantes e na manifestação de possíveis líderes, não participava das atividades em grupo. Para diminuir a distância com o grupo realizava apenas os vitalizadores e algumas dinâmicas.

A média de participantes foi de 20,3 pessoas por módulo acompanhado, lembrando que o número mínimo de pessoas para iniciarem o programa é de 17 pessoas/módulo. O módulo com o maior número de participantes foi o de Administração Rural (AR) em Pirassununga, com 29 pessoas, enquanto que o menor número registrado foi também em um módulo de $A R$ em Irapuã, com 14 participantes.

Esta experiência propiciou a compreensão de uma série de fenômenos desencadeados pela metodologia, dentre os quais, pode ser destacado o processo de interação e estabelecimento de relações sociais indicados por Barros (1977), e algumas mudanças comportamentais, como apontado por Popadiuk e Marcondes (2000).

A promoção da interação entre os participantes é iniciada já no primeiro módulo de Organização Social (OS), no qual, após a apresentação institucional do SEBRAE e apresentação pessoal do facilitador, inicia-se uma dinâmica de apresentação dos participantes. Em um dos módulos observados, os participantes formavam duplas e perguntavam ao seu colega o nome, sua atividade, um sonho, um animal, devendo produzir um crachá para ele com o seu nome.

Os "vitalizadores" utilizados no programa consistem em atividades, exercícios estruturados e simulações de curta duração ligadas ao tema central do curso, que sejam: compatíveis com a cultura do grupo; aplicáveis como atividades iniciais em diferentes programas para se obter um clima de descontração grupal; como preparação para atividades subseqüentes; para ambientar os participantes; para elevar a motivação do grupo e para promover mais ação ou relaxamento de acordo com os objetivos propostos (SEBRAE/SP, 2001).

$\mathrm{Na}$ medida em que as atividades eram desenvolvidas, os participantes se tornavam mais descontraídos e participativos, expondo suas opiniões com mais freqüência. $\mathrm{Na}$ metade do segundo dia de atividades do módulo de OS, já era possível notar, em alguns casos, que os participantes já possuíam características de um grupo.

Sem dúvida, este módulo era o que possuía o maior número de atividades, dinâmicas e jogos, objetivando justamente fazer com que ocorresse a formação de um grupo. Vale ressaltar que para cada atividade geralmente eram estabelecidos grupos diversos, a fim de colocar o maior número de pessoas diferentes em contato mais próximo.

Para o programa, era muito importante que ao término do módulo de OS as pessoas já se sentissem em um grupo, pois o segundo módulo, de Custos de Produção (CP), não possuía atividades focadas nesta finalidade. As atividades eram mais objetivas, embora os exercícios realizados exigissem muito diálogo entre as pessoas dos subgrupos formados.

Neste módulo os grupos eram formados apenas em dois momentos (um em cada dia), o primeiro aleatoriamente para atividades de balanço patrimonial, e o segundo, de acordo com a atividade agropecuária que desenvolviam para que facilitasse 0 aprendizado e despertasse maior interesse sobre custos de produção. Em alguns grupos, pelo fato de sua heterogeneidade nesse quesito, não era possível realizar a divisão dos 
subgrupos de acordo com o perfil produtivo, dificultando os trabalhos individuais.

Praticamente 0 mesmo ocorreu no módulo seguinte, em Comercialização Agrícola (CA), em que eram realizadas atividades mais objetivas e, em algumas delas, eram mantidos os grupos estabelecidos no módulo anterior.

Somente no último módulo, Administração Rural (AR), havia uma flexibilidade maior para algumas dinâmicas, pois novamente os facilitadores dispunham de um leque maior de atividades não objetivas, onde 0 intuito de fortalecer a necessidade de formar-se de fato um grupo coeso voltava à tona. Provavelmente porque se trata do último módulo e exige-se, ao seu término, que o grupo estabeleça e desenvolva metas específicas. No entanto, é fato que o módulo de Organização Social trabalha enfaticamente esta finalidade.

Foi interessante notar que, neste módulo, as pessoas já se acostumavam a desenvolver as atividades práticas do curso, pois se organizavam e iniciavam as atividades em si numa velocidade maior do que a notada em outros módulos, e mesmo em relação ao acompanhamento, no qual passavam praticamente um mês afastados do âmbito do programa. No segundo módulo (Custos de Produção), há uma conscientização da existência de atividades em grupo, assim, a receptividade e organização já são maiores que no módulo de Organização Social.

Ao final da etapa de treinamento, e principalmente nos acompanhamentos realizados por facilitadores do SEBRAE/SP, notou-se, em alguns grupos, geralmente aqueles com os participantes mais próximos da realidade de público alvo do programa, que houve 0 estabelecimento de relações sociais, mudança de atitudes, comportamento e valores, principalmente em relação à necessidade de maior profissionalismo no setor e visão empresarial.
Seria realmente interessante para as atividades objetivas, iniciadas no módulo de Custos de Produção e finalizadas no módulo de Administração Rural, que fosse mantida a mesma estrutura de subgrupos formata no módulo de Custos de Produção, visto que os módulos são etapas subseqüentes de trabalho e aprendizagem, e como pôde ser acompanhada, a não realização dessa prática, gera dúvidas e dificuldades.

Outra questão a ser comentada se relaciona ao fato dos grupos claramente preferirem as atividades práticas, ou dinâmicas, em detrimento à simples explanação sobre o conteúdo teórico dos diversos assuntos. A participação, atenção e concentração sempre foram maiores quando eram realizadas estas atividades.

Em todas as fases do programa, com exceção do módulo de Custos de Produção, foram utilizados filmes de vídeo com temas institucionais, motivacionais e instrutivos que auxiliavam $\mathrm{o}$ processo de aprendizagem e reforçavam as teorias apresentadas.

A metodologia participativa tinha por finalidade evitar que as informações fossem provenientes apenas dos instrutores/facilitadores, dando oportunidade ao público de contribuir com sua experiência e, principalmente, sua realidade, na elaboração do curso (expectativas, problemas, etc.). Esta abertura para a participação do público proporcionou maior alcance aos grupos de pessoas e ajudou no processo de interação, inclusive com os facilitadores, pois o grupo sentiase importante e auxiliava no andamento das atividades.

Parte das atividades realizadas no programa utilizava a técnica do "Ciclo de Aprendizagem Vivencial" (CAV), cuja importância está no fato do grupo compartilhar as reações e emoções individuais vivenciadas durante a realização de algum jogo ou dinâmica e, 
principalmente, discutir as facilidades e dificuldades encontradas, culminando com a análise de seu próprio desempenho e padrões de comportamento no grupo.

A infraestrutura colocada à disposição do programa variou fortemente nos 24 locais em que se realizou a observação das atividades de capacitação. De forma geral, os intervalos, as cadeiras/mesas disponíveis, a acústica, o conforto térmico, o tamanho das salas, e principalmente, a qualidade das projeções de transparências, deixaram a desejar. Em contrapartida, os álbuns seriados disponibilizados, os quadros (branco e negro), a acústica das salas, sua localidade e o material apostilado foram os melhores itens encontrados (Tabela 1 e Figura 1).

Tabela 1. Infraestrutura disponível no Programa de Capacitação Rural.

$\begin{array}{lccccc} & \text { MUITO BOM } & \text { SATISFATORIO } & \text { INSATISFATÓRIO } & \text { TOTAL } \\ \text { Conforto térmico } & 9 & 12 & 9 & 30 \\ \text { Localidade } & 16 & 11 & 3 & 30 \\ \text { Tamanho da sala } & 7 & 12 & 11 & 30 \\ \text { Acústica } & 14 & 7 & 9 & 30 \\ \text { Cadeiras/mesas } & 7 & 15 & 8 & 30 \\ \text { Flip chart } & 10 & 15 & 2 & 27 \\ \text { Quadro } & 11 & 5 & 3 & 19 \\ \text { Retroprojetor } & 6 & 19 & 5 & 30 \\ \text { Projeção } & 1 & 14 & 15 & 30 \\ \text { Tv/vídeo } & 3 & 9 & 2 & 14 \\ \text { Imagem do filme } & 4 & 6 & 4 & 14 \\ \text { Apostilas } & 14 & 6 & 4 & 24 \\ \text { Coffe break } & 6 & 16 & 8 & 30\end{array}$

Os itens mencionados como insatisfatórios podem, de alguma forma, ter contribuído para o estabelecimento de ruídos ou barreiras na comunicação, como mencionado por Berlo (1960), Burke e Molina (1979) e Machado Filho (1977). Estes autores entendem por ruídos de comunicação, quaisquer elementos que venham a interferir na qualidade da comunicação e do estabelecimento de seu processo, sendo fundamental para a eficácia da capacitação.

Identificar e localizar os possíveis ruídos, a partir das informações que a retroalimentação do processo fornece, torna possível à fonte de informação tentar eliminá-los ou mesmo minimizá-los, substituindo códigos, reestruturando as mensagens, trocando os veículos ou os canais de comunicação, até conseguir confirmar que seus objetivos foram atingidos.

Destaca-se, primordialmente, a qualidade das projeções de transparências, pelo fato de ser, juntamente com o álbum seriado e o quadro, o recurso mais utilizado pelos facilitadores.

O material apostilado apresentou queda de qualidade na fase final do acompanhamento, pelo fato do término aparente dos estoques do SEBRAE/SP. Com isso, muitos participantes criticaram as apostilas, por tratar-se de simples cópia sem encadernação. Isto ocorreu em quatro casos, enquanto que em outros nove casos, houve a encadernação da apostila.

Torna-se importante esclarecer que os materiais didáticos elaborados e disponibilizados 
pelo SEBRAE/SP durante os diversos módulos do Programa Capacitação Rural eram de extrema qualidade física e visual. As apostilas (uma para cada módulo), especialmente, eram materiais produzidos em gráfica, coloridos, encadernados com capa de papel especial e aspiral. Quando os participantes recebiam apostilas fotocopiadas sentiam-se extremamente desconfortáveis com a qualidade do material, pois se exigia a manutenção do "padrão SEBRAE". Tal fato repercutia negativamente no grupo, influenciando o andamento das atividades de capacitação.

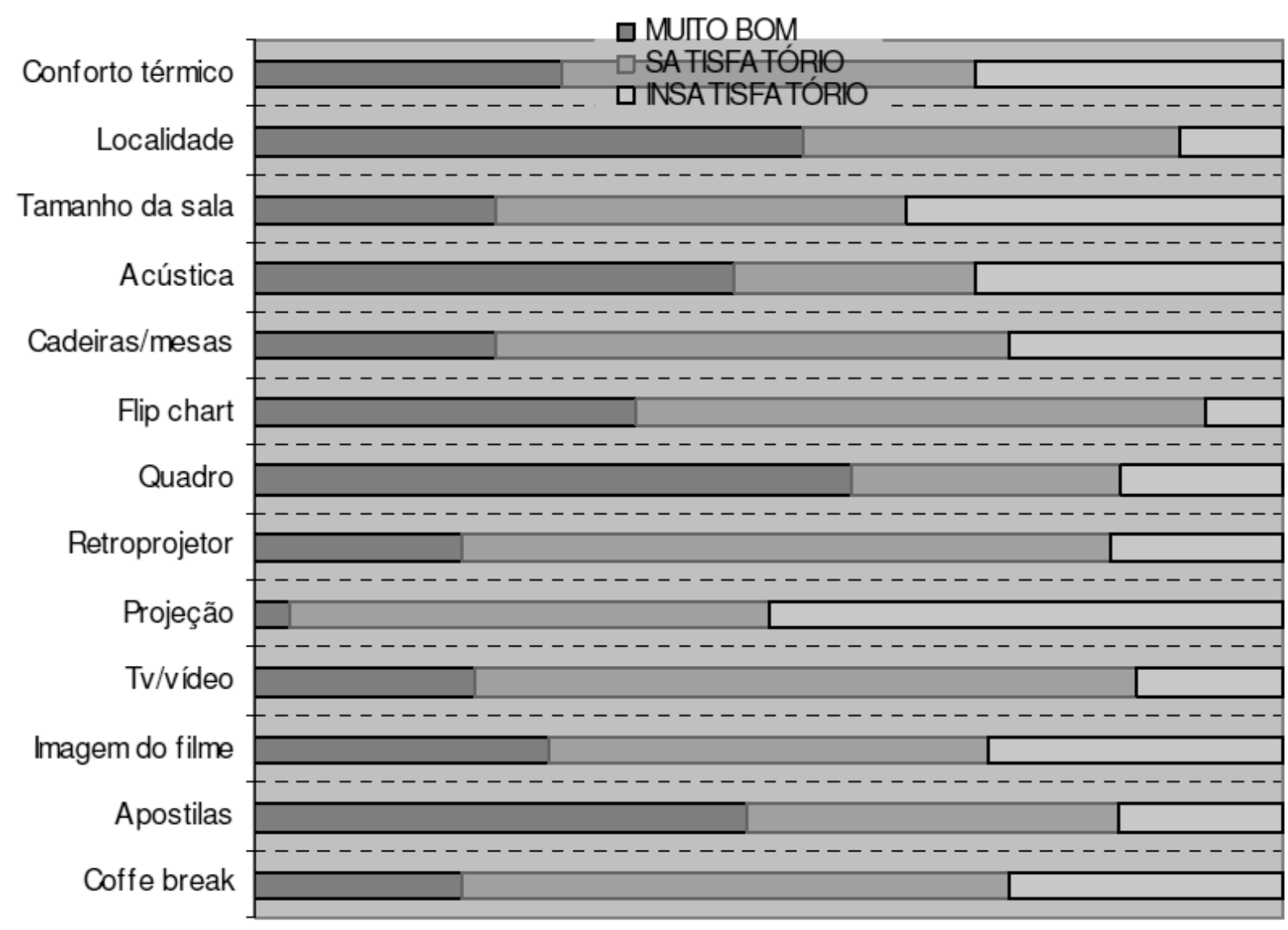

Figura 1. Infraestrutura disponível no Programa de Capacitação Rural.

Ao final de cada módulo, os participantes faziam uma avaliação, em questionário elaborado pelo SEBRAE/SP, no qual conceituavam diversos pontos da ação de capacitação. Em todo o período de observação foram encontradas três diferentes fichas de avaliação, das quais duas com bom conteúdo de avaliação, mas difícil classificação dos conceitos, e outra, ao contrário, com menor conteúdo de avaliação e mais fácil para conceituar.

A carga horária dos módulos observados ficou, em média, abaixo das 10 horas estabelecidas pelo manual de orientação metodológica do programa (média de 8,5 horas). Em alguns módulos a causa fundamental foi atribuída à velocidade com que as atividades eram desenvolvidas pelos subgrupos, demandando menos tempo para a conclusão das atividades previstas.

Os dias da semana e horários previstos para o início e término de certos módulos, mal planejados para este tipo de atividade, também contribuíram para a média encontrada. Houve muitas ações em finais de semana (1/3) e outras 
se iniciando às 13:00 com término previsto para as 23:00 horas, diminuindo naturalmente a disposição de grande parte das pessoas.

A data de início dos módulos, assim como os horários eram escolhidos pelos participantes ao final da palestra de sensibilização, na presença do facilitador e agente do SAI ou Escritório Regional, responsável pela implementação do programa.

Toda a carga de custos do programa tem como pilar fundamental a fase de sensibilização, uma etapa específica do programa, que tem por objetivo "convencer" os produtores rurais a participar. $\mathrm{Na}$ fase de sensibilização o público convidado recebe informações sobre a origem do programa, objetivos, sua estrutura, carga horária de trabalho e custos. Quanto maior e melhor o público das sensibilizações (mais focado ao alvo do programa), maiores as turmas e, quiçá, o número de turmas. A eficiência da sensibilização é diretamente relacionada a um bom planejamento da ação.

\section{b) Pesquisa de opinião com os participantes em relação ao processo de capacitação}

A pesquisa de opinião sobre o Programa Capacitação Rural foi realizada concomitantemente a uma caracterização dos participantes, com a aplicação de 467 questionários em 24 módulos de diferentes grupos de capacitação, no período de 14 de janeiro a 14 de setembro de 2003.

Os dados foram analisados, primeiramente, de forma global, considerando todos os participantes do programa que responderam ao questionário. Para analisar a opinião do principal segmento alvo do programa, foi isolado do banco de dados apenas aqueles que se consideraram produtores rurais.

As respostas foram organizadas $e$ tabuladas, sendo posteriormente calculadas as freqüências absolutas e relativas, a fim de obterse a distribuição em cada variável.

Por meio da análise modal das respostas (categorias com maior freqüência), foi possível observar que, em sua maioria, as pessoas que responderam ao questionário consideraram que o conteúdo da mensagem dos módulos iria ajudálas em suas atividades profissionais $(85,53)$, que as atividades em grupo ajudaram na aprendizagem do conhecimento (84,23\%), escolheram a projeção de transparências como recurso preferido $(44,32 \%)$, gostaram dos filmes exibidos $(67,17 \%)$, gostaram da apostila $(82,65)$, e principalmente, $91,58 \%$ ficaram bastante satisfeitos com os módulos. Além disso, 97,84\% das pessoas responderam que iriam utilizar o conhecimento que aprenderam no programa, $84,02 \%$ entenderam o facilitador com facilidade e $98,49 \%$ dos respondentes afirmaram que o facilitador manteve uma boa relação com o grupo.

Esses resultados apontam para um elevado nível de satisfação dos grupos que foram capacitados pelo programa, com destaque para as variáveis referentes às "atividades em grupo", "conteúdo da mensagem", "satisfação" e "adoção do conhecimento", cujas respostas favoráveis obtiveram freqüências elevadas.

A Análise de Correspondência entre as variáveis "escolaridade" e "atividades em grupo" indica que os participantes com menor nível de escolaridade vêem as atividades em grupo como essenciais para a compreensão do conteúdo abordado no programa de capacitação (Figura 2). 


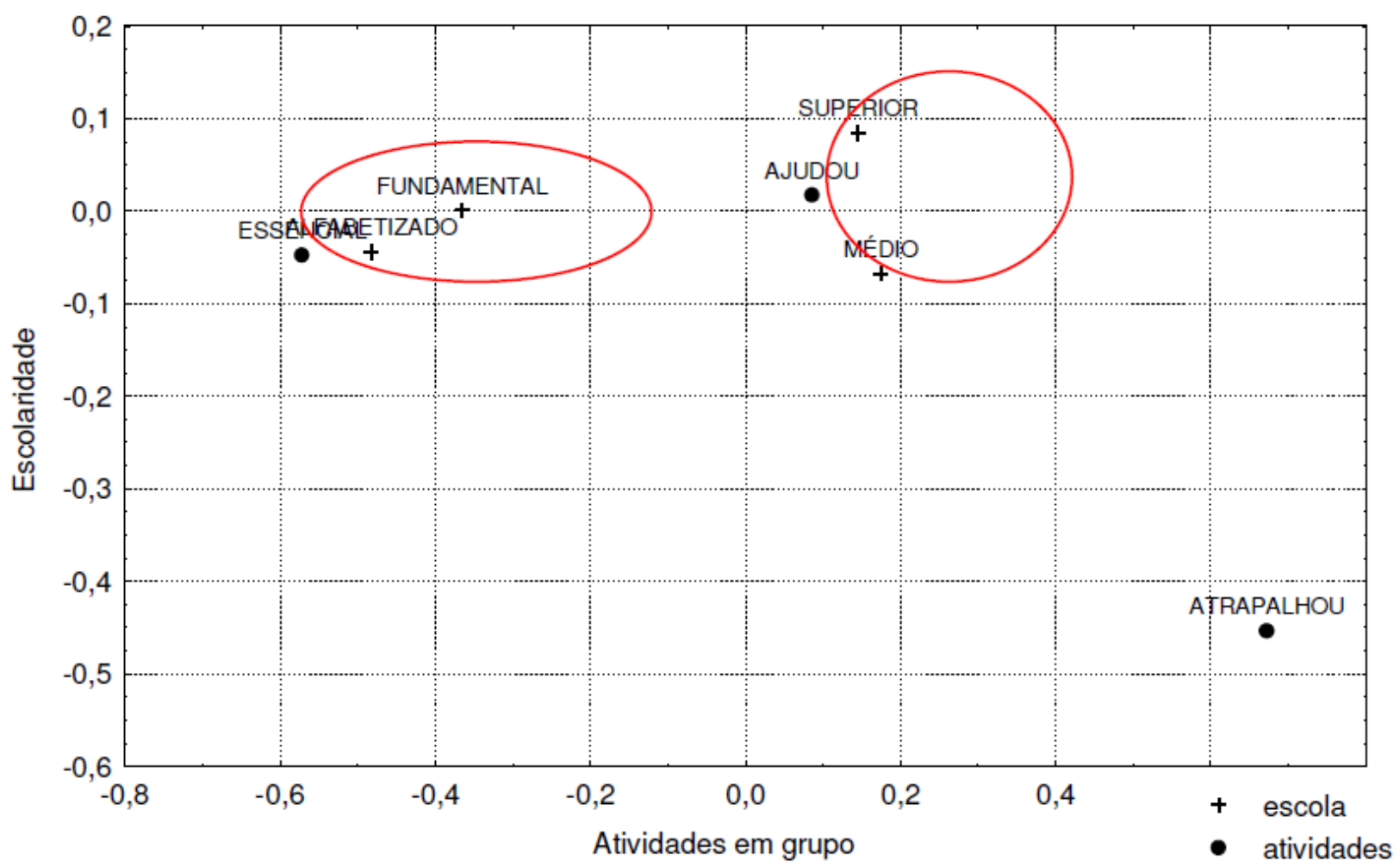

Figura 2. Análise de Correspondência entre as variáveis Escolaridade e Atividades em Grupo.

O percentual de pessoas que tiveram alguma dificuldade em compreender o facilitador também chama a atenção (15,55\%), número elevado ao considerar-se que o programa foi delineado e formatado para atingir um público alvo formado por produtores rurais com baixo nível de escolaridade, sendo os facilitadores selecionados e treinados para este fim. Este fato pode acarretar problemas na eficácia do programa, ou seja, na utilização do conhecimento transmitido no âmbito do programa, e a efetiva adoção desse conhecimento. Devido à elevada heterogeneidade dos grupos em relação à escolaridade, as pessoas com nível mais baixo de escolaridade talvez não estivessem conseguindo, em alguns casos, acompanhar o ritmo desenvolvido por seus colegas de turma.

A Análise de Correspondência entre as variáveis "escolaridade" e "entendeu o facilitador" corrobora esta constatação, apontando que as pessoas com nível fundamental correspondem àquelas com maior dificuldade em entender 0 facilitador (Figura 3).

Temos, portanto, que as pessoas com baixo nível de escolaridade têm, ao mesmo tempo, maior dificuldade em entender o facilitador e maior necessidade de realizar as atividades em grupo para compreender melhor o conteúdo do programa de capacitação. 


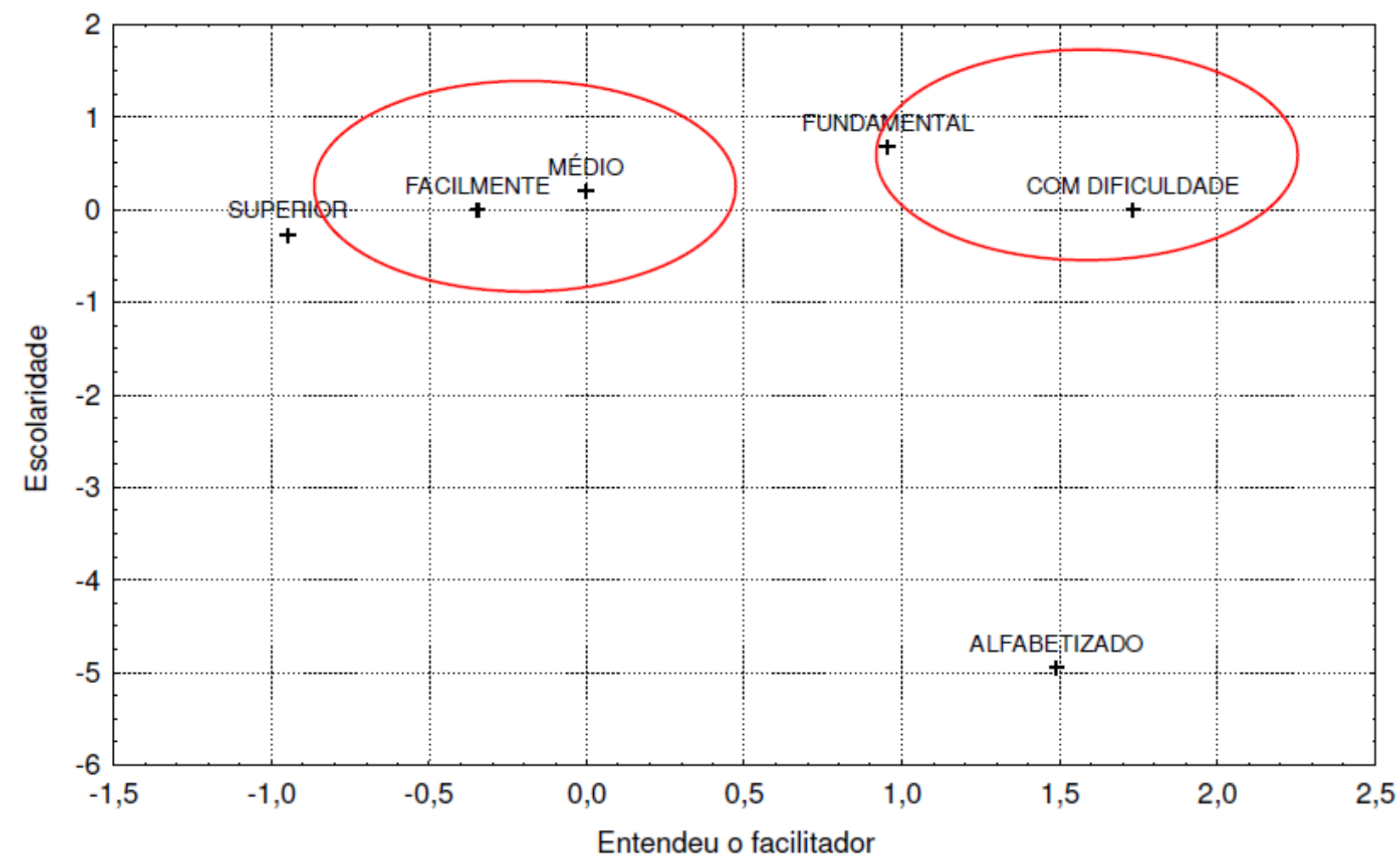

Figura 3. Análise de Múltipla Correspondência entre as variáveis "Escolaridade" e "Entendeu o Facilitador".

Em outra Análise de Correspondência utilizando a variável "escolaridade", mas agora associada aos "recursos em geral", observou-se que as pessoas com nível superior preferiram a utilização do álbum seriado (flip chart), as de nível médio o recurso das transparências, enquanto os respondentes de escolaridade fundamental preferiram o quadro negro e os filmes. As pessoas alfabetizadas tendem a preferir os filmes (Figura 4).

Parte dos participantes considerou que o material apostilado estava desatualizado
$(17,35 \%)$, fato este reconhecido pelos próprios facilitadores dos diversos módulos, e que mostra uma necessidade específica de adequação do programa. Contudo, apenas $1,08 \%$ dos participantes não gostaram da apostila e 2,60\% tiveram dificuldade para entender o que estava escrito, seja por problemas de compreensão ou mesmo por problemas no material fotocopiado distribuído em alguns módulos. 


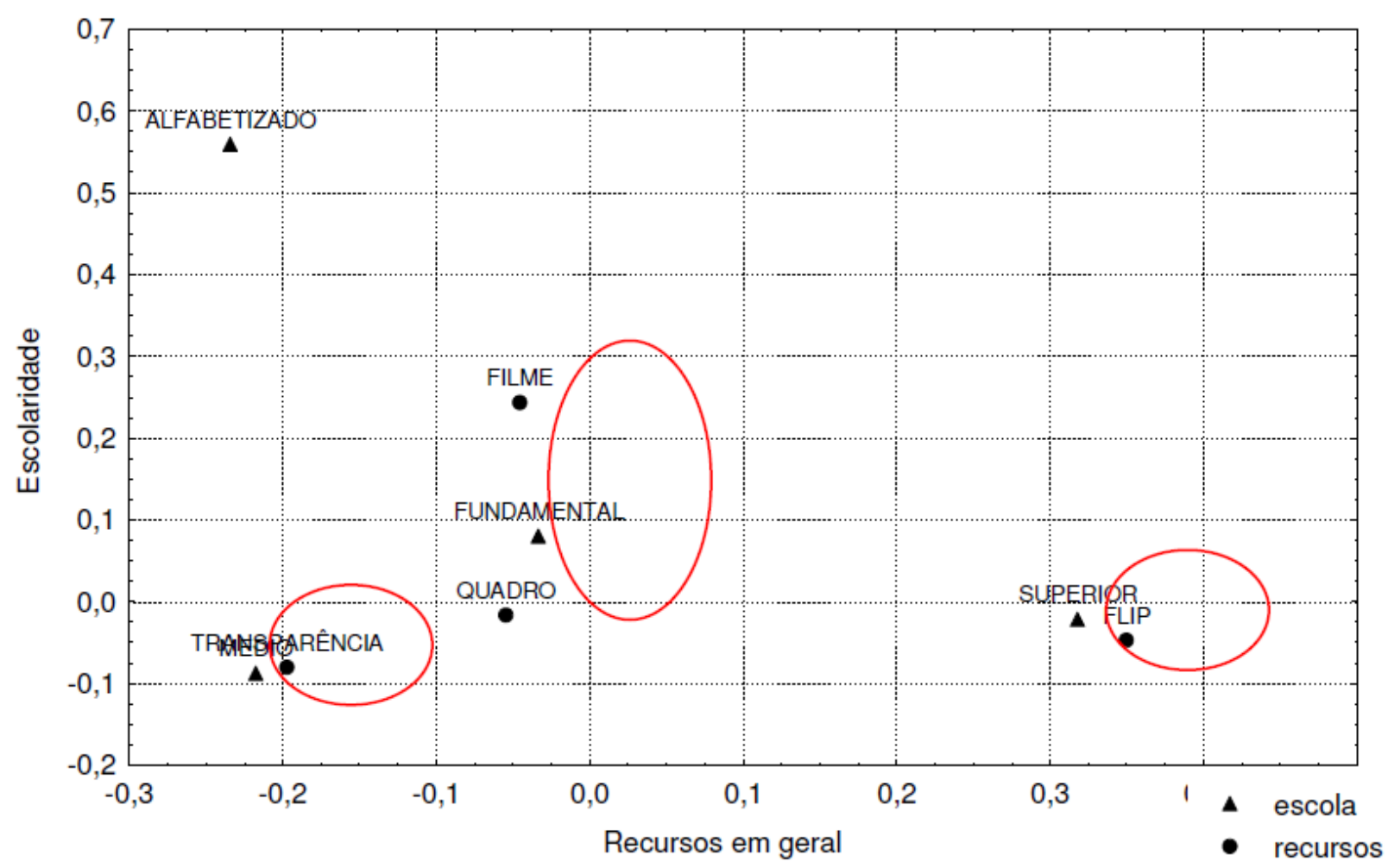

Figura 4. Análise de Correspondência entre as variáveis "Escolaridade" e "Recursos Audiovisuais em Geral".

As freqüências obtidas nas respostas favoráveis à "satisfação" (91,58\%) e "adoção do conhecimento" (98,49\%) foram muito expressivas, e apontam o impacto positivo do processo de capacitação no público participante (expectativa de adoção), já que, por exemplo, a adoção do conhecimento foi mensurada ao final dos módulos de capacitação, e não algum tempo depois do término do programa.

A Análise de Correspondência entre as variáveis "satisfação" e "ocupação principal", aponta que a parcela de pessoas que ficaram bastante satisfeitas com o programa corresponde aos produtores rurais e aos técnicos (Figura 5). 


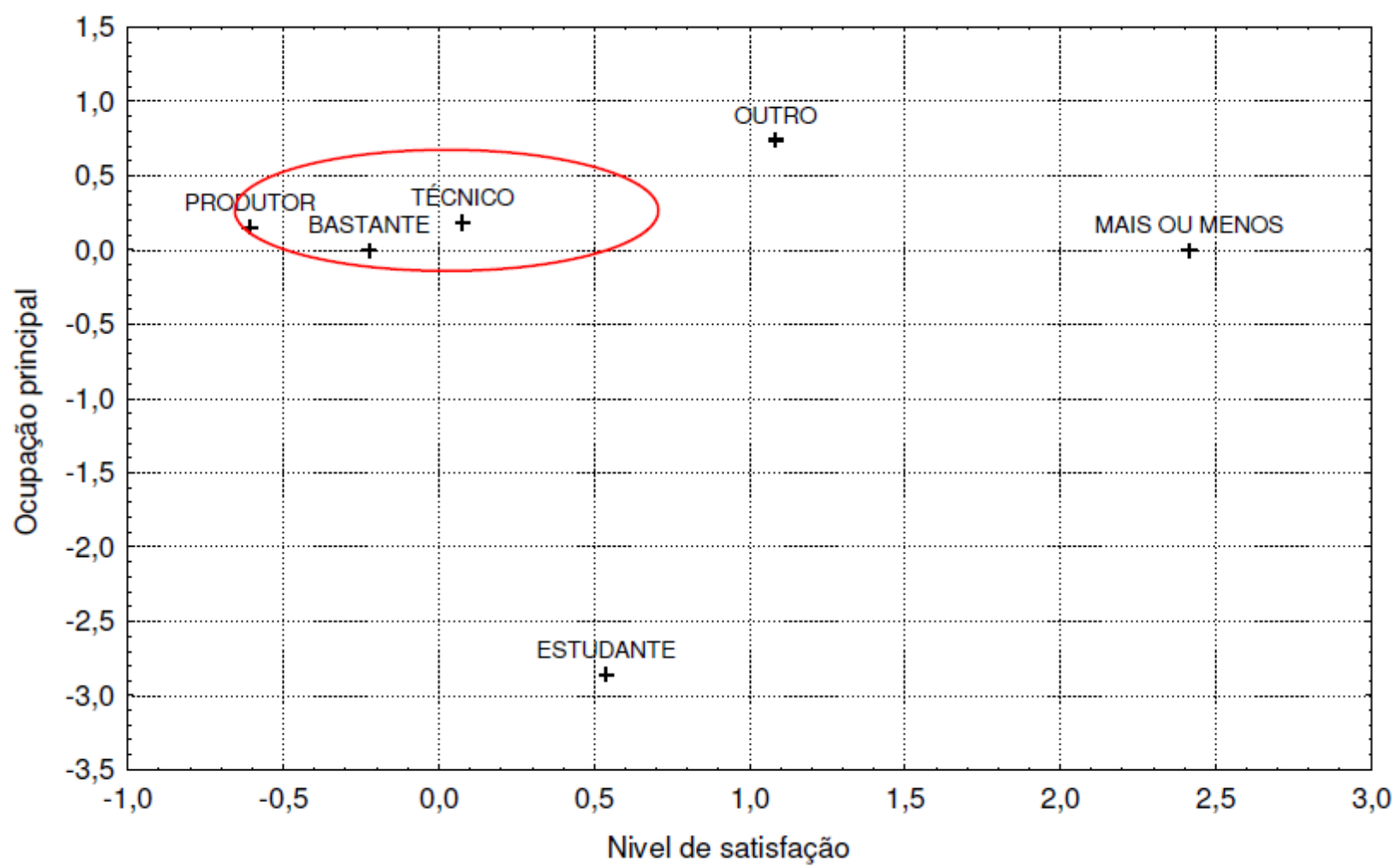

Figura 5. Análise de correspondência entre as variáveis "ocupação principal" e "nível de satisfação".

O Programa Capacitação Rural deve ser entendido como um processo de capacitação, no qual, cada etapa subseqüente é complementar à anterior. Este caráter lhe confere enorme complexidade, e para que não ocorram prejuízos em sua eficácia, ou mesmo danos à credibilidade institucional do SEBRAE, e profissionais envolvidos, é necessário que receba a mesma conotação de um "produto", em que a padronização de procedimentos é primordial.

Sua metodologia é moderna, quando comparada a diferentes formas de atuação na difusão de tecnologias em geral, the conferindo grande potencial de persuasão no meio rural. A participação das pessoas, efetivamente, traz resultados favoráveis e auxilia na consolidação dos grupos.

Durante o processo de capacitação, as pessoas se acostumam a realizar atividades práticas de diferentes naturezas, geralmente em grupo, sejam envolvidas com as atividades de produção, ou mesmo relacionadas a outras questões menos objetivas, como o estabelecimento de metas e a condução de reuniões.

A grande heterogeneidade observada nos grupos do programa, nesse caso específico em relação à atividade produtiva, trouxe problemas na formação dos subgrupos que exigiam perfil produtivo semelhante. Esses subgrupos são necessários nos módulos de Custos de Produção, Comercialização Agrícola e Administração Rural, e os participantes que se submetiam a desenvolver as atividades práticas com temas não relacionados a sua realidade produtiva, em geral, não aproveitavam esta oportunidade da melhor forma, por simples desmotivação.

Nas 30 observações realizadas durante a pesquisa, a infraestrutura encontrada deixou a desejar em algumas oportunidades, mas em geral, na maioria dos lugares pelo menos um item trazia prejuízo ao processo de comunicação.

Em algumas ocasiões as ações de capacitação ocorriam nos finais de semana, ou 
em horários desfavoráveis (das 13:00 às 23:00 horas), entretanto, atividades de difusão desenvolvidas no mesmo horário de trabalho dos produtores rurais são interpretadas e encaradas com maior responsabilidade e comprometimento, ao passo que ocupar os horários livres para o lazer e convívio com a família, com cursos da natureza do Programa Capacitação Rural que exigem cansativo desprendimento mental, prejudica o rendimento do grupo ao longo do processo de capacitação.

A pesquisa de opinião sobre o programa de capacitação mostrou níveis de aprovação muito elevados em diferentes variáveis analisadas, dentre elas as atividades em grupo, o conteúdo da mensagem, a satisfação e a adoção do novo conhecimento.

Os resultados mostraram que um elevado percentual de pessoas tem dificuldade em entender o facilitador (15,5\%), o que traria problemas na eficácia do programa. Este fato tem correspondência com o baixo nível de escolaridade desses participantes. As pessoas com menor nível escolar também correspondem àquelas que consideram as atividades em grupo essenciais para a compreensão do conteúdo dos módulos.

A grande heterogeneidade da escolaridade dos participantes pode acarretar na dificuldade de compreensão dos participantes, visto que a agilidade das pessoas com nível escolar mais elevado em realizar as tarefas e atividades práticas poderiam estar prejudicando as outras pessoas. Assim, poderíamos ter um quadro em que as pessoas consideradas, teoricamente, o segmento alvo do programa, e com mais necessidade na capacitação, estariam com maiores dificuldades de entender os facilitadores.

Os elevados níveis de satisfação e adoção obtidos têm relação com 0 impacto positivo do processo de capacitação e sua metodologia. Isto porque essas informações são levantadas ao final dos módulos do programa, durante 0 encerramento. De forma geral, as pessoas que ficaram mais satisfeitas correspondem aos participantes que tem a produção rural ou atividades técnicas na área rural como ocupação principal.

\section{CONCLUSÃO}

O Programa Capacitação Rural, possui elevados níveis de satisfação dentre seus participantes, inclusive os produtores rurais. Promove alterações comportamentais, de atitudes e valores, e enfatiza a necessidade de profissionalismo e valorização no meio rural.

\section{REFERÊNCIAS}

ABRAMOVAY, R. Organização Rural e Capacitação dos Atores. Nota Técnica (Relatório Final). In: Programa Estadual de Microbacias Hidrográficas, São Paulo, 2004.

\section{ALMEIDA, J.A. Pesquisa em extensão rural:} um manual de metodologia. Brasília: Associação Brasileira de Educação Agrícola Superior, 1989. 182p.

APEC TREINAMENTOS. Treinamento dos recursos humanos rurais. Penápolis / SP. 2003. Disponível em:

www.apectreinamentos.com.br/apec/rural.htm. Acesso em: 20 de outubro de 2003.

BARROS, E.V. Alguns aspectos da estrutura agrária brasileira para os agentes de mudança. In: CICOBRA. CURSO DE EXTENSÃO E COMUNICAÇÃO RURAL PARA TÉCNICOS DA ANPL, 1., Viçosa: Nestlé, 1977. p.90-107. BATISTA JÚNIOR, P.N. Mitos da globalização. Estudos Avançados, v. 12, n. 32, p. 125-186, 1998. 
BENZËCRI, J. P. L'analyse des donnés. Tome II. L'analyse des correspondances. Paris: Dunod, 1973. $75 p$.

BERLO, D.K. O processo da comunicação. 4 ed. Rio de Janeiro: Fundo de Cultura, 1960. 270p. BOURRUCHE, R.; SAPORA, N. Análise de dados. São Paulo: Atlas, 1980. 120p.

BURKE, T.J.; MOLINA, F. Fundamentos teóricos e instrumentos para a assistência técnica à agricultura. Piracicaba: ESALQ/USP. Série

Didática n.43, 1979.

CAMPOS, R.L.S. Capacitação rural: o caso do SAI - Sistema Agroindustrial Integrado do SEBRAE-SP - módulo de Araraquara. Revista

Espaço de Diálogo e Desconexão, v.1, n.1, p.14, 2008.

COBRA, M. Administração de marketing. 2. ed. São Paulo: Atlas, 1992. 806p.

FIRETTI, R. ; FRANZOLIN, R. ; RIBEIRO, M.M.L.O. . Análise do Programa Capacitação Rural SEBRAE/SP e caracterização dos participantes. Organizações Rurais e

Agroindustriais, v. 8, n.2, p. 176-189, 2006.

FIRETTI, R. ; RIBEIRO, M.M.L.O. .

Reorganização dos mercados agroalimentares: globalização, concorrência e difusão tecnológica. In: Marcelo Machado Luca Oliveira Ribeiro; Celso da Costa Carrer. (Org.). Agropecuária e Desenvolvimento - Diagnóstico, Tecnologia e as Questões Emergentes. São Paulo: Edições Loyola, 1999, v. 1, p. 61-85.

FIRETTI, R.; RIBEIRO, M.M.L.O. Cooperativismo e assistência técnica: novos parâmetros para ação. Acta Scientiarum, v. 23, n. 4, p. 10451054, 2001.

KOTLER, P. Marketing. São Paulo: Atlas, 1996. 560p.

LOURENZANI, W.L.; PINTO, L.B. Proposta metodológica para a capacitação gerencial de agricultores familiares. In: 46ํㅡㄹ Congresso da Sociedade Brasileira de Economia, Administração e Sociologia Rural, 2008, Campo Grande. Anais do Congresso da SOBER. Piracicaba: SOBER, 2008. v.46.

MAALOUF, W.D. Recursos humanos e desenvolvimento agrícola sustentado. São Paulo: Fundação Salim Farah Maluf, 1993. 45 p.

MACHADO FILHO, F. O processo de tomada de decisão. In: CICOBRA. CURSO DE EXTENSÃO E COMUNICAÇÃO RURAL PARA TÉCNICOS DA ANPL, 1. Viçosa: Nestlé, 1977. p.153-158.

OLIVEIRA, J. O empreendedorismo rural e a política de capacitação profissional em pequenas propriedades rurais na região de Araraquara.

Revista Espaço de Diálogo e Desconexão, v.1, n.1, p.1-5, 2008.

POPADIUK, S.; MARCONDES, R.C. Marketing social como instrumento facilitador de mudanças organizacionais: uma aplicação ao processo de privatização. Cadernos de Administração, v.1, n.12, p.42-53, 2000.

\section{SEBRAE/SP. Projeto Capacitação Rural:} manual do instrutor. São Paulo: SEBRAE/SP, 2000. $46 p$

\section{SEBRAE/SP. Apostila metodológica do}

Programa Capacitação Rural. São Paulo.

Divisão de Educação e Treinamento

SEBRAE/SP, 2001. 66p.

SEBRAE/SP. Desenvolvimento do Programa Capacitação Rural - SEBRAE/SP. Comunicação Pessoal. 2003. Departamento de Agronegócios SEBRAE/SP. 2003a

SEBRAE/SP. Regulamento de credenciamento de facilitadores: projeto capacitação rural SEBRAE/SP. 2003. Disponível em: http://www.sebraesp.com.br/editais. Acesso em 5 de junho de 2001. 2003b 
SILVA, E.; VERDINELLI, M. A. Avaliação em massa de terrenos em Blumenau Santa

Catarina - Brasil usando análises fatorial de correspondência e regressão múltipla. Textos para Discussão, UFSC CSE / Departamento de Ciências Econômicas, n.9, 1997.

SOARES, M.M. O SEBRAE e o agronegócio. In: Agronegócio brasileiro: ciência, tecnologia e competitividade. Brasília: CNPq, 1998. p. 141152.

SOUSA, K.S., SANT ANA, A.L., TARSITANO, M.A.A. Planejamento, capacitação técnica e adoção de tecnologia: os fatores que afetam as decisões dos produtores familiares do cinturão verde de llha Solteira (SP). In: $46^{\circ}$ Congresso da Sociedade Brasileira de Economia, Administração e Sociologia Rural, 2008, Campo Grande. Anais do Congresso da SOBER. Piracicaba: SOBER, 2008. v.46.

UOEDCE Metodologia de aplicação do Programa Capacitação Rural - SEBRAE/SP.

São Paulo: Unidade Organizacional de Educação e Desenvolvimento da Cultura Empreendedora SEBRAE/SP, 2001. 70p.

VIEIRA, E.M., NITZCHE, T.; KOLLER DA SILVA, A. O Programa SAI e seu efeito na capacitação do empresário rural do Alto Tietê - SP. In: 44ํㅜㅇ Congresso da Sociedade Brasileira de Economia, Administração e Sociologia Rural, 2006, Fortaleza. Anais do Congresso da SOBER.

Brasília: SOBER, 2006. v.44.

WILDEMUTH, B. M. Post-positivist research: two examples of methodological pluralism. Library

Quarterly, v.63, n.4, p.450-468, 1993. 